\title{
Bot to Monitor Student Activities on E- learning System Based on Robotic Process Automation (RPA)
}

\author{
Ghifari Munawar* \\ Jurusan Teknik Komputer dan Informatika, Politeknik Negeri Bandung \\ ghifari.munawar@polban.ac.id
}

\begin{abstract}
Submitted : Sep 9, 2021 | Accepted : Oct 10, 2021 | Published :Oct 10, 2021
\end{abstract}
\begin{abstract}
Student activities in the e-learning system need to be monitored regularly by lecturers to observe their learning achievements. The monitoring process carried out is monitoring student attendance, collecting assignments, and taking quizzes. This will be a burden if they do regularly it, especially if the lecturer teaches many subjects. Robotic process automation (RPA) is a technology that uses software agents (bots) to imitate human work processes to be automated. Objectives of this research are (1) applying RPA technology as bots that can monitor student activity on the e-learning system (Moodle), and (2) measuring the time efficiency of RPA bots in processing their work. The research stages are divided into three, namely: the preparation stage, the RPA implementation stage, and the evaluation stage. It carried the preparation stage out to define the problem to be handled, the RPA implementation stage to develop bots using the UiPath platform, and the evaluation stage to compare the efficiency of work time between bots and manually (by humans). I developed the RPA bot on four work focuses, namely (1) attendance monitoring, (2) task collection monitoring, (3) quiz processing monitoring, and (4) email delivery automation. Efficiency testing was carried out on four test scenarios (FR1, FR2, FR3, FR4), where FR2 had the highest percentage of work time efficiency at $754 \%$, and the lowest was in FR1 with a percentage of $165 \%$, with an overall average efficiency percentage of $444 \%$. Thus, through RPA technology, monitoring work becomes faster and saves effort.
\end{abstract}

Keywords: Bot; E-learning System (Moodle); Monitor Student Activities; Robotic Process Automation (RPA); UiPath;

\section{INTRODUCTION}

Using e-learning systems as online learning media during the COVID-19 pandemic in universities has increased. The form of lectures, both tutorial lectures, seminars, and practicums which were originally carried out face-to-face have moved to virtual spaces, this affects increasing the intensity of the use of e-learning systems in universities, and making it a space to achieve learning objectives (Wijaya, Lukman, \& Yadewani, 2020). Moodle is one of the most widely used e-learning platforms and can be customized as needed (Nash, 2018). Moodle plays a role in increasing students' motivation and interest in carrying out learning activities in virtual spaces (Oproiu, 2015), which can affect the learning outcomes (Rudi Haryadi, 2021).

Student activities in the e-learning system can be a factor that predicts success or failure in fulfilling their learning achievements (Raga \& Raga, 2017), so lecturers need to do regular monitoring. Several things that can be monitored in the e-learning system are (1) lecture attendance, (2) assignment collection, and (3) quizzes. Lecturers need to know these activities as an indicator of whether their students have attended online lectures well. Good activities such as attending lectures, collecting assignments, and doing quizzes given in the e-learning system will support learning success, and vice versa, bad activities such as rarely attending lectures, rarely collecting assignments, and rarely doing quizzes will risk causing failure. Lecturers need to know as early as possible these activities so they can consider the right steps for the future.

Moodle has a feature to monitor every student learning activity that the lecture can access directly to find out information related to lecture attendance, assignment collection, and quiz results. This monitoring process will be a burden if it is carried out regularly and repeatedly every week, especially if the lecturer teaches several courses *Name of the corresponding author 
at once in one semester. One solution is to use robotic process automation (RPA) technology that can replace the role of lecturers in monitoring student activity in the e-learning system through the development of bots.

RPA is a relatively new technology which uses software agents called "bots" to imitate human work processes on an application system (Syed et al., 2020). The tasks that bots run are usually rule-based, well-structured, and repetitive (Ivančić, Suša Vugec, \& Bosilj Vukšić, 2019). RPA bots can help to do some tedious tasks such as filling out input forms in the application system (Sutipitakwong \& Jamsri, 2020), replying to emails automatically, or collecting data (scrapping) from various sources (Syed et al., 2020). Currently, RPA technology has been used in various domains, including the banking industry, insurance, health institutions, accountants (Syed et al., 2020), audit institutions (Moffitt, Rozario, \& Vasarhelyi, 2018), and educational institutions (Lasso-Rodríguez \& GilHerrera, 2019)(Lasso-Rodríguez \& Gil-Herrera, 2020)(Guacales-Gualavisi, Salazar-Fierro, García-Santillán, Arciniega-Hidrobo, \& García-Santillán, 2021)(Turcu \& Turcu, 2018). The utilization of RPA bots in executing work can increase time efficiency up to $995.43 \%$ (Guacales-Gualavisi et al., 2021), this has a significant impact on the time required to complete work compared to being done manually (by humans). The application of RPA in higher education provides several advantages, including reducing costs, saving time, increasing work value, improving management skills, and improving the learning experience for students and lecturers (Turcu \& Turcu, 2018).

Two main points are the goals of this research, namely: (1) applying RPA technology as bots that can monitor student activity on the e-learning system (Moodle), and (2) measuring the time efficiency of RPA bots in processing their work. I used the UiPath as a platform in building the automation process because it is the most popular and easiest to use tool (Khan, 2020). In its implementation, the stages of this research are divided into the preparation stage, the RPA implementation stage, and the evaluation stage, while the e-learning system that is the object of this research is the e-learning system (Moodle) which is used in the Politeknik Negeri Bandung.

\section{METHOD}

To meet the research objectives, it is necessary to develop a systematic method so that each stage can be carried out optimally. This research method is divided into three stages, namely: (1) the preparation stage, (2) the implementation stage of the RPA, and (3) the evaluation stage, as described in Figure 1. The activities carried out in each stage are described in more detail in the subsections below.

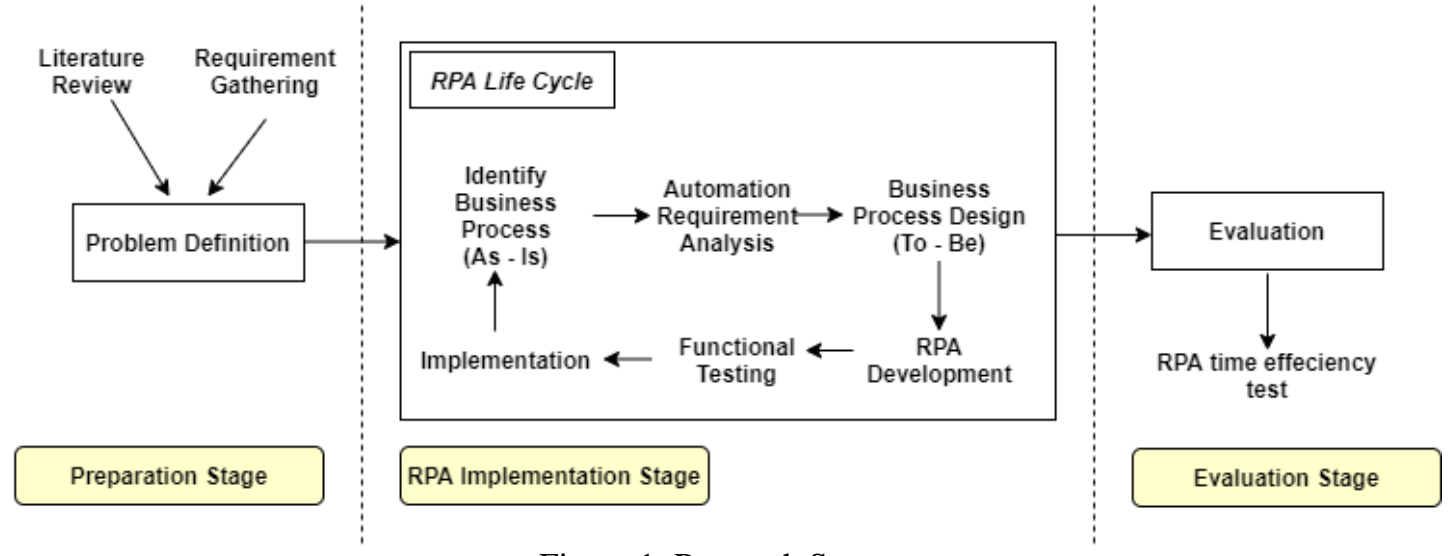

Figure 1. Research Stages

\section{Preparation Stage}

I carried the preparatory stage out through literature study activities to study research related to RPA technology and its application, while I carried requirements gathering activities out to explore information related to the problems to be handled. At this stage, the need for RPA development tools is also prepared as UiPath Studio IDE as tools in RPA project management (Nandan Mullakara, 2020), Windows 10 operating system, MS Office 365, .NET Framework, and Bizagi applications for modeling business processes.

\section{RPA Implementation Stage}

The RPA implementation stage is the bot development stage from the problems that have been defined in the previous stage. Similar to software development, RPA has a life cycle with activities starting from (1) identification of business processes (as-is), (2) analysis of automation requirements, (3) design of automation business processes (to-be), (4) RPA development, (5) functional testing, and (6) implementation. The business process identification stage (as-is) is carried out to study the business processes running on the e-learning system related to monitoring *Name of the corresponding author 
work carried out by lecturers such as monitoring student attendance through the attendance feature, monitoring task collection through the assignment feature, and monitoring the results of quizzes through the feature quizzes. The automation needs analysis stage is carried out to analyze business processes that have the potential to be automated by RPA or those that do not go through a process analysis approach (Leshob, Bourgouin, \& Renard, 2018). The business process design stage (to-be) is carried out to model the business process according to the results of its automation needs. The RPA bot development stage is carried out to implement the RPA bot using the UiPath platform according to the designed process steps. The functional testing phase is carried out to ensure the bot has worked according to its functionality. The RPA bot implementation phase is carried out to prepare the bot to run on the test device. This activity is carried out sequentially at each stage to get a bot that suits the needs. The specifications of the devices used at this implementation stage are:

\begin{tabular}{ll} 
& Table 1. RPA Bot Development Kit Specifications \\
\hline Component & Device Specifications \\
\hline Processor & Intel ${ }^{\circledR}$ Core ${ }^{\mathrm{TM}}$ i7-8555OU \\
\hline Memory & 16384 MB RAM \\
\hline OS & Windows 10 Home \\
\hline Hard Disk & 1 TB SSD \\
\hline Internet Access & 10 Mbps \\
\hline IDE & UiPath Studio Pro 2021 4.4 Community License \\
\hline Office App & Microsoft Office 365 \\
\hline Business Process Modelling & Bizagi Modeler \\
\hline Browser & Internet Explorer 11 \\
\hline Screen Recorder App & OBS Studio 25.0.8 (64 bit) \\
\hline
\end{tabular}

\section{Evaluation Stage}

The evaluation stage is carried out to measure the time efficiency required by the RPA bot in processing the work of monitoring student activities on the e-learning system compared to being done manually (by the lecturers). The time measurement mechanism is carried out by measuring the execution time of work between bots and manually using a screen recorder in seconds. The two results of execution time will then be compared and the level of efficiency measured as a percentage.

\section{RESULT}

\section{Business Process Design Automation (to-be)}

Business processes (to-be) designed for automation are monitoring work in filling attendance, collecting assignments, taking quizzes, and automating email delivery. The object of the application in this study is the Politeknik Negeri Bandung's e-learning system that uses the LMS Moodle. To design the automation business process, I identified each stage of the work according to the business processes running in the system. How are the steps taken by the lecturers in monitoring attendance on e-learning, monitoring task collection, monitoring quiz work, and sending emails. As long as the work is done in a well-structured manner, there is no behavior change in the system / it is always repetitive, and the rules are clear (rule-based), then the process can be automated using an RPA bot. The business process design (to-be) for each of these jobs is described in the subsections below.

\section{Attendance Monitoring}

The lecturers can do the attendance monitoring process by first filling in the monitoring input form with input parameters as courses, meeting weeks, the type of monitoring as attendance, and the status to be monitored whether present or absent. The RPA bot will do the work to get the attendance data on the e-learning system so as an attendance report in excel form. 


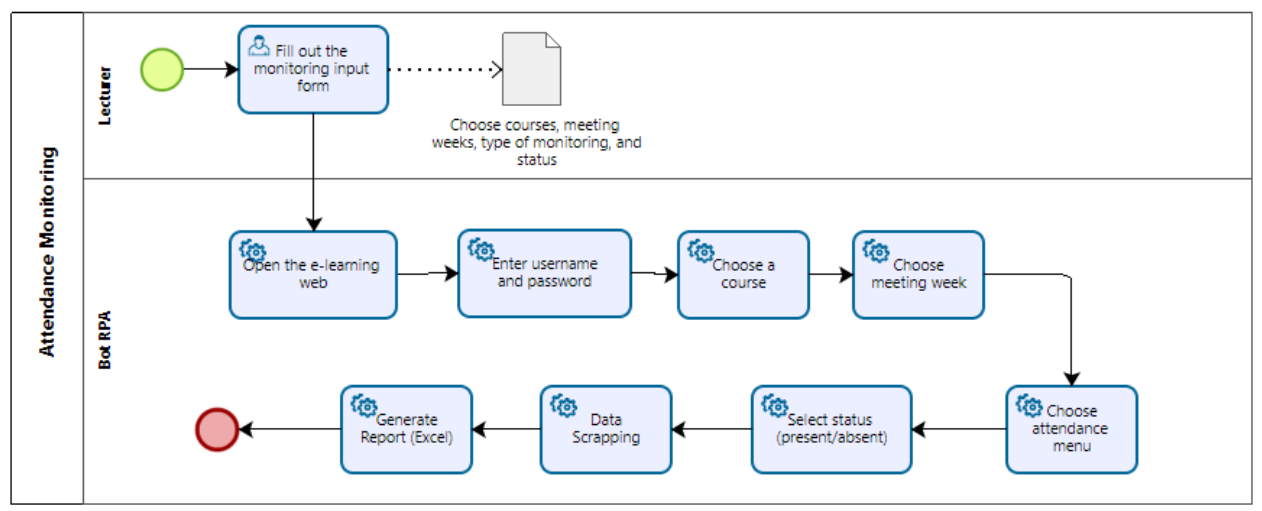

Figure 2. Attendance monitoring business process

\section{Assignment Collection Monitoring}

Monitoring the collection of assignments is carried out by filling in the input form of choice parameters as courses, week of meetings, the type of monitoring selected as assignments, and the status of whether or not submitted. After the parameters are determined, the RPA bot will process the work on the e-learning system so as a task collection report in excel form.

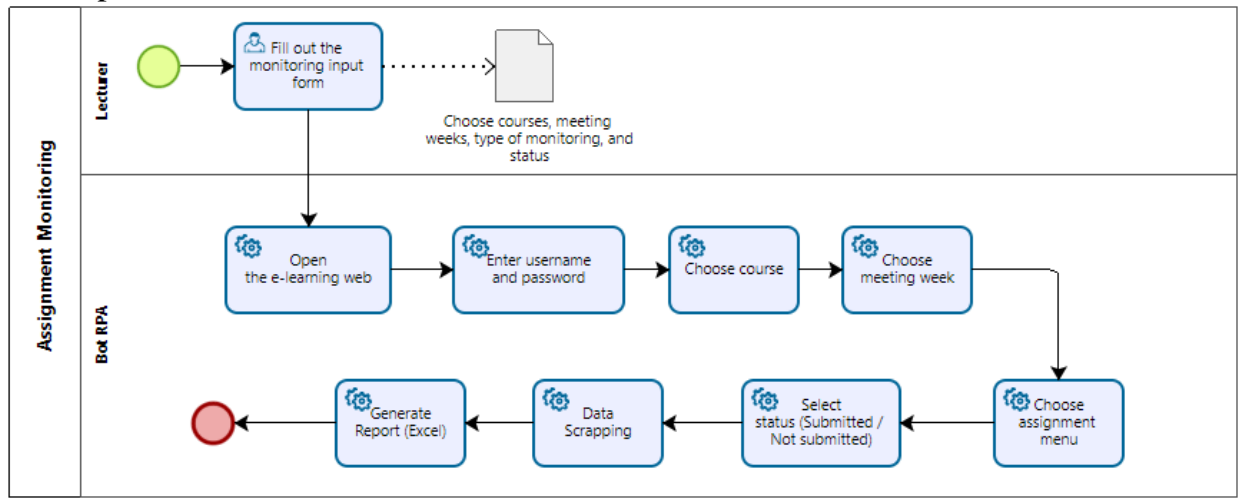

Figure 3. Assignment monitoring business process

\section{Quizzes Monitoring}

The monitoring process for the quizzes is done by filling in the input form with optional parameters as courses, meeting weeks, and the type of monitoring selected as quizzes. The RPA bot will process the work, including checking the status of passing whether passed or failed. To get the status passed, the minimum score on the quiz is 70. It gave the result as a quiz report as an excel file.

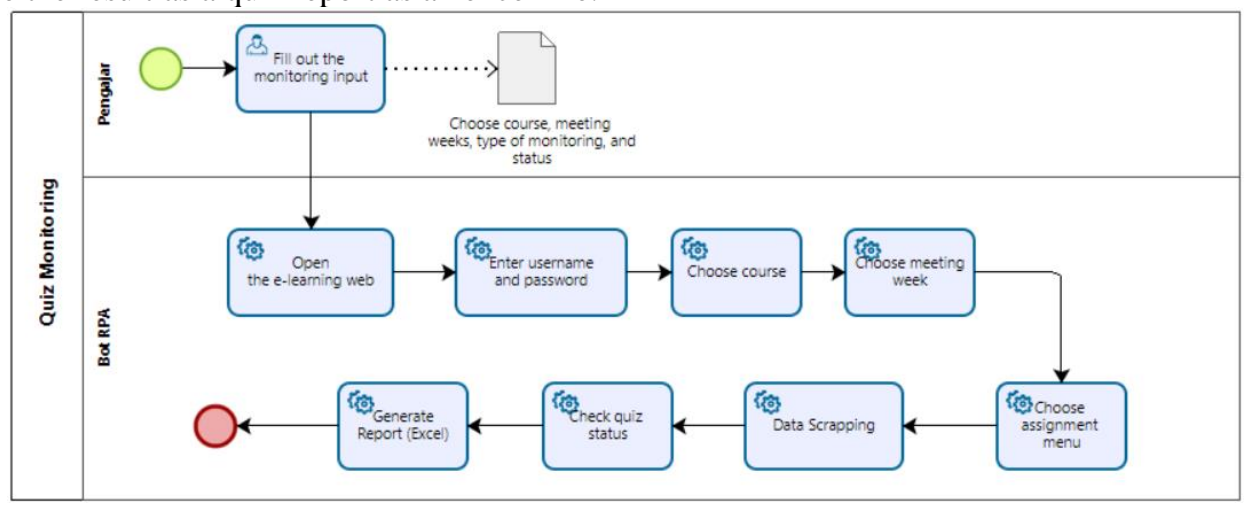

Figure 4. Quiz monitoring business process

*Name of the corresponding author 


\section{Email Delivery Automation}

Automating email delivery is done by filling in an email sending form containing the subject and body of the message, as well as a list of email recipients as an excel file. Next, the RPA bot will email each recipient via SMTP Mail Message according to the subject and body of the message.

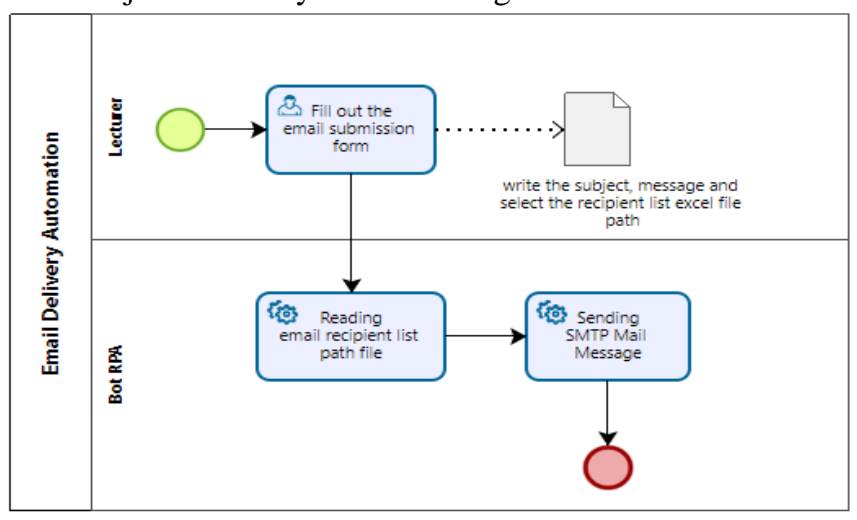

Figure 5. Email delivery automation business processs

\section{RPA Bot Development}

The designed to-be business process was then developed through the UiPath Studio IDE with the project layout as a sequence. The consideration of choosing sequence as the layout is when the process flow has clear steps without many conditions with a top-down approach pattern. The automation developed follows the business process flow with more detailed steps using the activity components that have been provided, such as open browser, click, type into, select item, data scraping, and accessing excel application. The programming language used is Visual Basic (VB). To facilitate bot development and testing, each automation business process is created in a different project, namely (1) attendance monitoring bot, (2) task collection monitoring bot, (3) quiz monitoring bot, and (4) email delivery automation bot. Figure 6 is an example of the display of the task collection monitoring bot sequence on UiPath. It can be seen that the flow of the stages of the automation process is arranged sequentially, the detailed steps for the stages are written in Table 2.

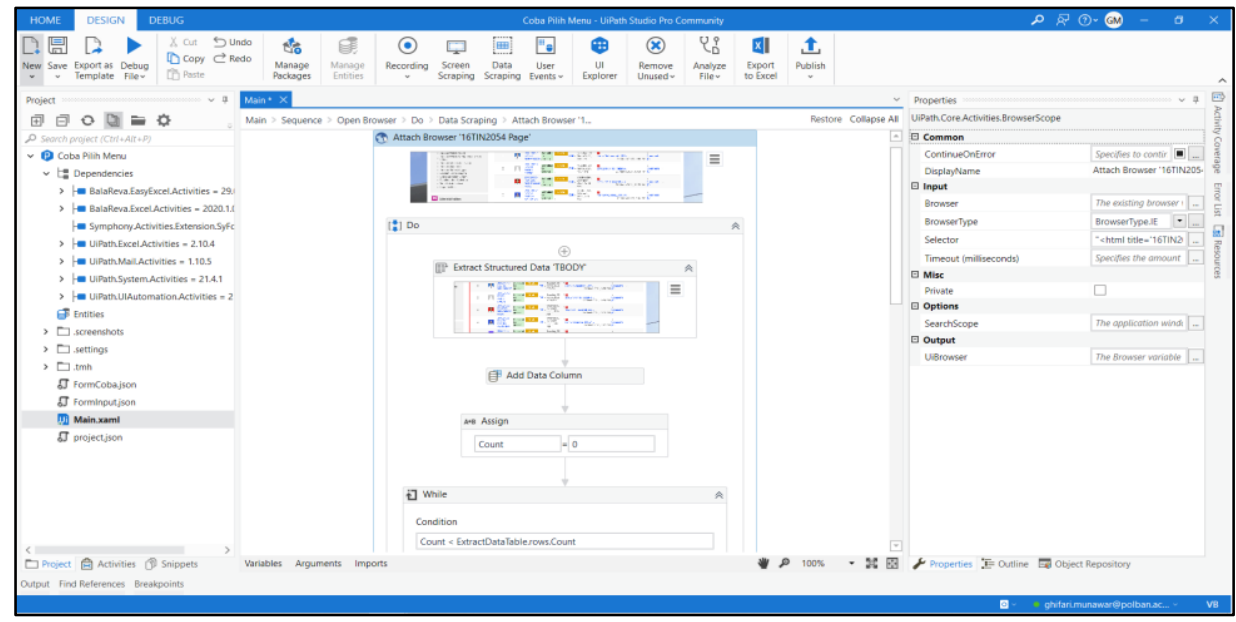

Figure 6. Sequence - assignment collection monitoring bot

Table 2. Bot RPA process steps for assignment collection monitoring

\begin{tabular}{|cll|}
\hline No & \multicolumn{1}{c|}{ Bot RPA Process Steps } & \multicolumn{1}{c|}{ UiPath Activity Component } \\
\hline 1 & Displays the monitoring input form & Symphony.Extensions.SyForms.ShowForm \\
\hline 2 & Access the e-learning system & UiPath.Core.Activities.OpenBrowser \\
\hline 3 & Enter username & UiPath.Core.Activities.TypeInto \\
\hline 4 & Enter password & UiPath.Core.Activities.TypeInto \\
\hline 5 & Click the submit button & UiPath.Core.Activities.Click \\
\hline 6 & Choose a course menu & UiPath.Core.Activities.Click \\
\hline
\end{tabular}

*Name of the corresponding author 


\begin{tabular}{|c|c|c|}
\hline 7 & Click meeting week button & UiPath.Core.Activities.Click \\
\hline 8 & Click the assignment submission link & UiPath.Core.Activities.Click \\
\hline 9 & Click the View all submission button & UiPath.Core.Activities.Click \\
\hline 10 & Click the dropdown Assignments per page & UiPath.Core.Activities.Click \\
\hline 11 & Select the item All & UiPath.Core.Activities.SelectItem \\
\hline 12 & Select the Filters dropdown & UiPath.Core.Activities.Click \\
\hline 13 & Select the item status (Submitted / Not submitted) & UiPath.Core.Activities.SelectItem \\
\hline 14 & Execute data scrapping & System.Activities.Statements.Sequence \\
\hline 15 & Select data table & UiPath.Core.Activities.BrowserScope \\
\hline 16 & Extract data table & UiPath.Core.Activities.ExtractData \\
\hline 17 & Add Email column & UiPath.Core.Activities.AddDataColumn \\
\hline 18 & Assign variable $i=0$ & System.Activities.Statements.Assign \\
\hline 19 & Looping data table & UiPath.Core.Activities.InterruptibleWhile \\
\hline 20 & Assign variable $\mathrm{dr}=$ DataTable $\operatorname{Row}(i)$ & System.Activities.Statements.Assign \\
\hline 21 & Navigate to student profile url $-i$ & UiPath.Core.Activities.NavigateTo \\
\hline 23 & Retrieves student email string $-i$ & UiPath.Core.Activities.GetVisibleText \\
\hline 24 & Assign variable $\operatorname{dr}(2)=$ outputEmail & System.Activities.Statements.Assign \\
\hline 25 & Assign variable $i=i+1$ & System.Activities.Statements.Assign \\
\hline 26 & Write data in excel file (generate report) & UiPath.Excel.Activities.ExcelApplicationScope \\
\hline 27 & Write the report title in cell A1 & UiPath.Excel.Activities.ExcelWriteCell \\
\hline 28 & Write the report status in cell $\mathrm{A} 2$ & UiPath.Excel.Activities.ExcelWriteCell \\
\hline 29 & Write the range according to data table in cell A4 & UiPath.Excel.Activities.ExcelWriteRange \\
\hline 30 & Setting style in excel file & BalaReva.EasyExcel.Main.ExcelScope \\
\hline 31 & Set the style on cell A1 & BalaReva.EasyExcel.Sheets.CellFont \\
\hline 32 & Checking assignment submission status & System.Activities.Statements.If \\
\hline 33 & If status is Submitted then cell A2 is green & BalaReva.EasyExcel.Sheets.CellFont \\
\hline 34 & If status is Not submitted the cell A2 is red & BalaReva.EasyExcel.Sheets.CellFont \\
\hline 35 & Set font to bold in the data table header & BalaReva.EasyExcel.Sheets.CellFont \\
\hline 36 & Set border thickness for data table & BalaReva.EasyExcel.Sheets.SetBorder \\
\hline 37 & Set column width to autofit & BalaReva.EasyExcel.Sheets.AutoFitColumns \\
\hline 38 & Displays success message & UiPath.Core.Activities.MessageBox \\
\hline
\end{tabular}

In Table 2 there are 38 steps of the RPA process that are arranged for monitoring the collection of assignments, starting from displaying input forms to filling in course parameters, choosing the week of meeting, type of monitoring and status. Each inputted parameter will be processed in the next step sequentially. The process flow must be structured in detail and specifically so that RPA bots can imitate every step as lectures do for monitoring in e-learning systems. The output of this automation process is the production of a report (recap) of monitoring the collection of tasks as an excel file. The number of RPA process steps for other automation is 23 activities for automation of attendance monitoring, 42 activities for automation of monitoring quiz work, and 8 activities for automation of sending emails.

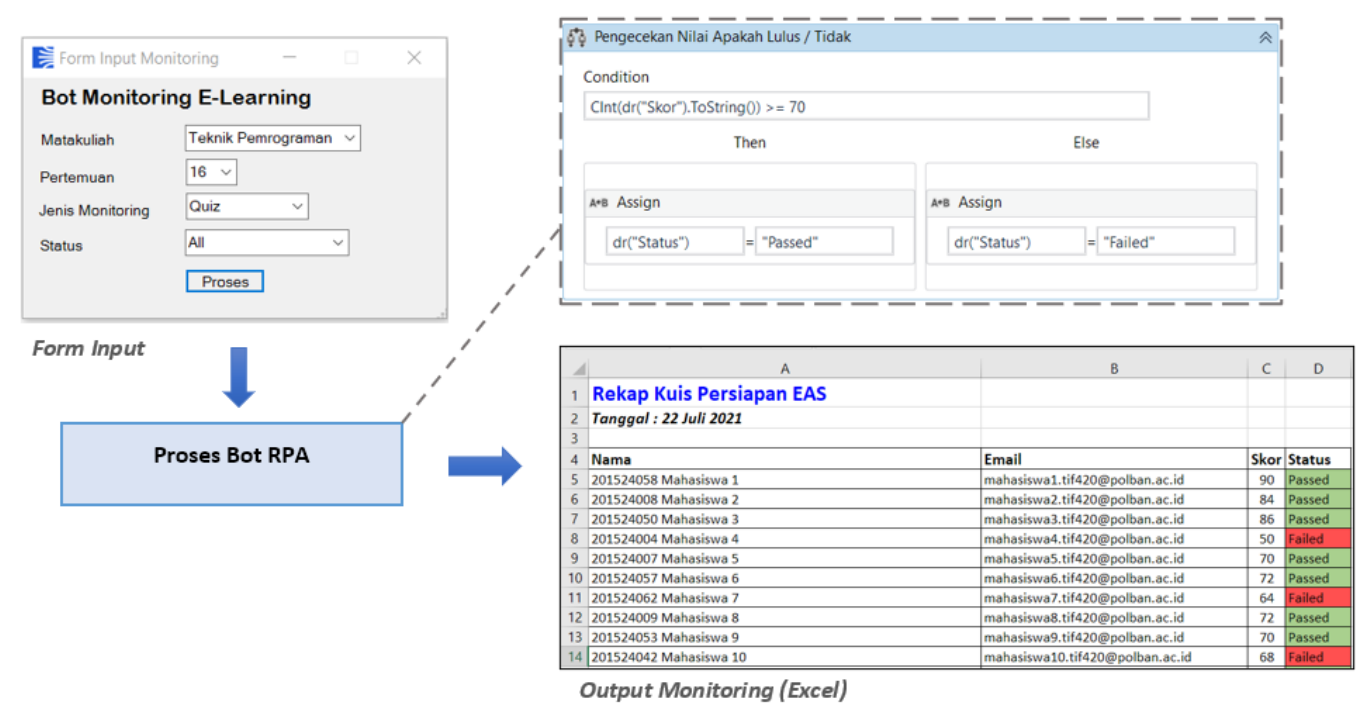

Figure 7. Bot RPA execution to monitor quiz activities

*Name of the corresponding author 
Figure 7 is an example of an execution bot for monitoring quiz activity. Each parameter is determined first through the input-form, then the RPA bot will process its work and produce an output as a recap in excel form. This output contains information needed by the lecturers, such as student name, email, score, and status (whether passed or failed). The RPA bot can process a condition. If the score is 70 , then the status is passed, if not then failed, including for setting the color of the cell (green for passed, and red for failed). This list of students is got through a data scrapping process on the e-learning system according to the parameters on the input form.

In the development of bots for email delivery automation, the UiPath activity component used is Send SMTP Mail Message. There are several properties that must be filled in these components, such as server host, port, logon email, and password. The subject and content of the message are written under the contents of the input form. As for emailing, a delivery loop is carried out according to the number of recipients, so that each recipient will get a message according to their respective emails. This is done to maintain the privacy of the recipient of the content of the message conveyed. The SMTP Mail account used in this study is a Gmail account. It needs to be configured first on the account so that it may open access for other applications.

\section{Functional Testing}

Before the RPA bot is implemented on the test device, I carried functional testing out first to ensure that every step of the automation process has run well. This process is carried out through debugging on the UiPath to observe the activities carried out by the bot sequentially. Table 3 shows the results of functional tests that have been carried out on 4 RPA bots that have been developed, namely FR1 for the attendance monitoring bot test scenario, FR2 for task collection monitoring bots, FR3 for quiz monitoring bots, and FR4 for email delivery automation bots. Based on the functional testing that has been done, all RPA bots can process their work properly according to the expected results.

Table 3. Functional Testing RPA Bot

\begin{tabular}{|c|c|c|c|c|c|}
\hline ID & Test Name & Test Condition & RPA Process & Expected Result & Status \\
\hline FR1 & $\begin{array}{l}\text { Attendance } \\
\text { Monitoring }\end{array}$ & $\begin{array}{l}\text { 1. Choose the course "Teknik } \\
\text { Pemrograman". } \\
\text { 2. Select the meeting week " } 2 \text { " } \\
\text { 3. Choose the type of monitoring } \\
\text { "Attendance" } \\
\text { 4. Select "All" Status }\end{array}$ & 23 Activity & $\begin{array}{l}\text { Attendence monitoring } \\
\text { report in excel form for } \\
\text { "Teknik Pemrograman" } \\
\text { course in week }-2 \text {. }\end{array}$ & Passed \\
\hline FR2 & $\begin{array}{l}\text { Task } \\
\text { Collection } \\
\text { Monitoring }\end{array}$ & $\begin{array}{l}\text { 1. Choose the course "Teknik } \\
\text { Pemrograman". } \\
\text { 2. Select the meeting week " } 1 \text { " } \\
\text { 3. Choose the type of monitoring } \\
\text { "Assignment" } \\
\text { 4. Select "Submitted" Status }\end{array}$ & 38 Activity & $\begin{array}{l}\text { Assignment collection } \\
\text { monitoring in excel form } \\
\text { for "Teknik } \\
\text { Pemrograman" course in } \\
\text { week - } 1 \text { with the status } \\
\text { "Submitted" }\end{array}$ & Passed \\
\hline FR3 & $\begin{array}{l}\text { Quiz } \\
\text { Monitoring }\end{array}$ & $\begin{array}{l}\text { 1. Choose the course "Teknik } \\
\text { Pemrograman". } \\
\text { 2. Select the meeting week " } 16 \text { " } \\
\text { 3. Choose the type of monitoring } \\
\text { "Quiz" } \\
\text { 4. Select "All" Status }\end{array}$ & 42 Activity & $\begin{array}{l}\text { Quiz monitoring report in } \\
\text { excel form for "Teknik } \\
\text { Pemrograman" course in } \\
\text { week }-16 \text {. }\end{array}$ & Passed \\
\hline FR4 & $\begin{array}{l}\text { Email } \\
\text { Delivery } \\
\text { Automation }\end{array}$ & $\begin{array}{l}\text { 1. Write the subject of the email } \\
\text { 2. Write the body of message } \\
\text { 3. Choose an excel file containing } \\
10 \text { recipient emails. }\end{array}$ & 8 Activity & $\begin{array}{l}\text { Email was successfully } \\
\text { sent to } 10 \text { recipients as } \\
\text { per subject and message. }\end{array}$ & Passed \\
\hline
\end{tabular}

\section{Implementation}

The RPA bot has been implemented on the test device with the specifications as written in Table 1 . In this study, I did not publish the RPA bot on the UiPath Orchestrator (https://cloud.uipath.com/) because it was only used internally, according to the needs of the tests that have been designed.

\section{DISCUSSIONS}

The evaluation is done by measuring the efficiency of execution time by RPA bots compared to manually. Some limitations in this test include the number of subjects being tested is 1 course, the number of e-learning participants is 62 students, the number of meetings is 1 meeting, and the measurement of execution time is carried *Name of the corresponding author 
out using OBS screen recording tools in seconds. This test is carried out based on the scenarios that have been compiled in Table 3. I showed the results of the comparison of execution time between RPA bots and manuals in graphical form in Figure 8.

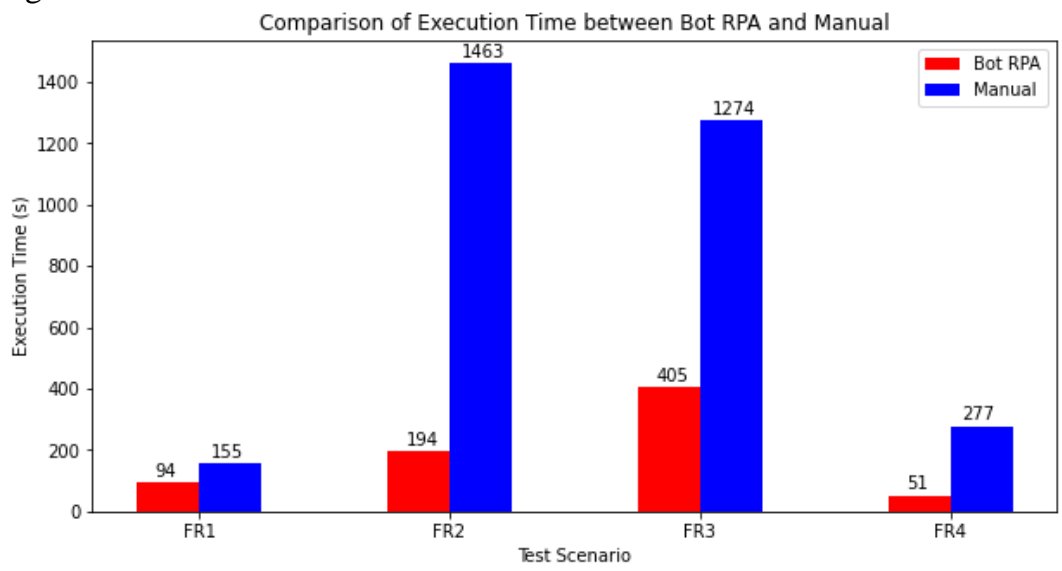

Figure 8. Comparison graph of execution time between bot RPA and manual

It can be seen based on the results of the execution time measurement in Figure 8, the RPA bot can process its work faster than manually for all test scenarios. The longest processing time for execution is FR2 and FR3, this is because the process steps are more and the activities carried out are more diverse (such as looping, data scrapping, conditions, and styling). Table 4 shows the percentage of execution time efficiency generated by the RPA bot.

Table 4. Execution time efficiency by Bot RPA

\begin{tabular}{cccc}
\hline ID & $\begin{array}{c}\text { Execution time of } \\
\text { Bot RPA }\end{array}$ & $\begin{array}{l}\text { Execution time of } \\
\text { manual }\end{array}$ & $\begin{array}{c}\text { Execution time efficiency } \\
\text { by Bot RPA }\end{array}$ \\
\hline FR1 & $94 \mathrm{~s}$ & $155 \mathrm{~s}$ & $165 \%$ \\
\hline FR2 & $194 \mathrm{~s}$ & $1463 \mathrm{~s}$ & $754 \%$ \\
\hline FR3 & $405 \mathrm{~s}$ & $1274 \mathrm{~s}$ & $315 \%$ \\
\hline FR4 & $51 \mathrm{~s}$ & $277 \mathrm{~s}$ & $543 \%$ \\
\hline
\end{tabular}

The RPA bot streamlined the highest job execution time in the FR2 test scenario with a percentage of $754 \%$, and the lowest on FR1 with a percentage of $165 \%$. These results show that the use of RPA bots in this study can speed up work execution time for monitoring student activity in the e-learning system compared to being done manually with an efficiency percentage of $444 \%$ if averaged for all test scenarios.

\section{CONCLUSION}

This research has developed an RPA bot for monitoring student activity in the e-learning system at the Politeknik Negeri Bandung with four work focuses, namely: (1) attendance monitoring, (2) task collection monitoring, (3) quiz work monitoring, and (4) automation of email delivery. The bot that has been developed has a faster job execution time than manually, with an average efficiency percentage of $444 \%$ against the four test scenarios. The UiPath platform used makes it easy for developers to make automation steps with the availability of various required activity components. Using RPA technology in this study can help lecturers to quickly monitor the condition of the learning outcomes of each student so that lecturers can make the right decisions to meet the learning objectives. Suggestions for research development is to add the concept of artificial intelligence (AI) or analytical data to the development of RPA bots to predict the success or failure of students in a course based on historical activities data in the e-learning system. It can become an early warning system (EWS) for lecturers to find out early on the possibilities that occur based on data analysis, so the parties concerned can receive quickly that information. These ideas will be something interesting to be developed in further research.

\section{ACKNOWLEDGMENT}

Acknowledgments are conveyed to the P3M unit in Politeknik Negeri Bandung which has provided financial support for this research with contract number 105.125/PL1.R7/PG.00.03/2021.

\section{REFERENCES}

Guacales-Gualavisi, M., Salazar-Fierro, F., García-Santillán, J., Arciniega-Hidrobo, S., \& García-Santillán, I. *Name of the corresponding author 
(2021). Computer System Based on Robotic Process Automation for Detecting Low Student Performance. https://doi.org/10.1007/978-3-030-68285-9_15

Ivančić, L., Suša Vugec, D., \& Bosilj Vukšić, V. (2019). Robotic Process Automation: Systematic Literature Review. Lecture Notes in Business Information Processing, 361(September), 280-295. https://doi.org/10.1007/978-3-030-30429-4_19

Khan, S. (2020). Comparative Analysis of Rpa Tools-Uipath, Automation Anywhere and Blueprism. International Journal of Computer Science and Mobile Applications, 8(11), 1-6. https://doi.org/10.47760/ijcsma.2020.v08i11.001

Lasso-Rodríguez, G., \& Gil-Herrera, R. (2019). Robotic Process Automation Applied To Education: a New Kind of Robot Teacher? ICERI2019 Proceedings, 1(November), 2531-2540. https://doi.org/10.21125/iceri.2019.0669

Lasso-Rodríguez, G., \& Gil-Herrera, R. (2020). Training the Teachers With Assistance of Robotic Process Automation. INTED2020 Proceedings, 1(March), 8714-8720. https://doi.org/10.21125/inted.2020.2373

Leshob, A., Bourgouin, A., \& Renard, L. (2018). Towards a Process Analysis Approach to Adopt Robotic Process Automation. Proceedings - 2018 IEEE 15th International Conference on e-Business Engineering, ICEBE 2018, 46-53. https://doi.org/10.1109/ICEBE.2018.00018

Moffitt, K. C., Rozario, A. M., \& Vasarhelyi, M. A. (2018). Robotic process automation for auditing. Journal of Emerging Technologies in Accounting, 15(1), 1-10. https://doi.org/10.2308/jeta-10589

Nandan Mullakara, A. K. A. (2020). Robotic Process Automation Projects. Retrieved from www.packt.com Nash, S. S. (2018). Moodle Course Design Best Practises (Second Edi). Retrieved from www.packtpub.com

Oproiu, G. C. (2015). A Study about Using E-learning Platform (Moodle) in University Teaching Process. Procedia - Social and Behavioral Sciences, 180(November 2014), $426-432$. https://doi.org/10.1016/j.sbspro.2015.02.140

Raga, R., \& Raga, J. (2017). Monitoring Class Activity and Predicting Student Performance Using Moodle Action Log Data. International Journal of Computing Sciences Research, 1(3), 1-16. https://doi.org/10.25147/ijcsr.2017.001.1.09

Rudi Haryadi, H. N. A. K. (2021). PENGARUH MEDIA PEMBELAJARAN E-LEARNING TERHADAP HASIL BELAJAR SISWA. At-Ta'lim, 7, 68-73. https://doi.org/https://doi.org/10.36835/attalim. v7i1.426

Sutipitakwong, S., \& Jamsri, P. (2020). The effectiveness of RPA in fine-tuning tedious tasks. Proceedings - 2020 6th International Conference on Engineering, Applied Sciences and Technology, ICEAST 2020, 8-11. https://doi.org/10.1109/ICEAST50382.2020.9165452

Syed, R., Suriadi, S., Adams, M., Bandara, W., Leemans, S. J. J., Ouyang, C., ... Reijers, H. A. (2020). Robotic Process Automation: Contemporary themes and challenges. Computers in Industry, 115, 103162. https://doi.org/10.1016/j.compind.2019.103162

Turcu, C., \& Turcu, C. (2018). On Robotic Process Automation and its Integration in Higher Education.

Wijaya, R., Lukman, M., \& Yadewani, D. (2020). Dampak Pandemi Covid-19 Terhadap Pemanfaatan E-Learning. Dimensi, 9(2), 307-322.

*Name of the corresponding author 